\title{
DISCRETE-EVENT SIMULATION FOR SPECIFICATION DESIGN OF PRODUCTS IN PRODUCT-SERVICE SYSTEMS
}

\author{
D. Kloock-Schreiber, R. Siqueira ${ }^{凶}$, P. C. Gembarski and R. Lachmayer \\ Leibniz Universität Hannover, Germany \\ $\bigotimes$ siqueira@ipeg.uni-hannover.de
}

\begin{abstract}
Boundaries between products and services vanish and companies increasingly offer hybrid solutions known as Product Service Systems (PSS). Thereby, a holistic view that includes both the product and service parts must be taken. This paper presents a discrete-event simulation of a PSS as a method for the specification of the product part. Besides product and service, the application scenario and the decision-making are also modeled. Based on the results for a case study, the customer requirements could be guaranteed as the essential product specifications were optimized to minimize total costs.
\end{abstract}

Keywords: product-service systems (PSS), simulation-based design, product development, discreteevent simulation

\section{Introduction}

Physical products can be extended by services and thus offered as a hybrid combination of products and services to differentiate the offering of a company from the competition (Gembarski et al., 2016). These offerings are described in the literature as Product Service Systems (PSS). Such PSS exist, but in most cases with services as an addition to an existing product. It is not desirable for manufacturers to add services to products, as this leads to discount demands. In order to take advantage of PSS, an integrative relationship between product and service that offers a customer real added value is necessary (Sturm et al., 2007).

A solution that can be precisely adapted to existing customer needs can create such real added value. PSS is described in the scientific literature as a solution that meets individual customer needs, regardless of whether the performance promise. Revenue is primarily achieved through the product or service parts. (Thomas et al., 2010)

The decision as to which business model should be pursued must be made at the beginning of development and has an influence on the requirements for the PSS and also on its development (Schreiber et al., n.d.). While product-oriented PSS are expected to have little impact on the development of the individual products (as parts of the PSS), other variants will have a much higher impact as the business model changes. This is the case, for instance, when a business model changes to a provider model and the products remain in the ownership of the operator. Therefore, not only is a customer-specific offer necessary but also the relationships between product and service parts. These relationships must be also taken into account during the planning of PSS to reduce development, operating and adaptation costs (Aurich et al., 2006). 
Depending on the business model and the associated services, the requirements placed on the product parts in a PSS also change. A smart product, which is equipped with sensors and data processing capabilities, can adapt to such changes autonomously. Nonetheless, the pool of reactions must be defined beforehand and consider the actual configuration of the PSS as well, since different product parts may have interdependencies (Gembarski, 2020). Given this huge amount of parameters and internal dependencies in PSS, there is a lack of methods in the literature for a product specification that fits this environment.

The objective of this paper is to build up a model which specify products in PSS based on a set of inputs and constraints. The inputs come from the PSS, which models the service, product and the decision making. The constraints results from the considered scenarios in which the PSS is implemented. Thereby, a discrete-event (DE) simulation is proposed as a method to investigate the influence of different PSS setups on the product design. Finally, service, product and customer's behavior were implemented in the example of coffee supply for a hotel.

The paper is structured as follows, in the state-of-the-art product service systems and event-discrete simulation are introduced. Subsequently, the modeling approach is presented and the case study is modelled. Then the simulation and the results are described and the paper is closed with a discussion and conclusion.

\section{State-of-the-art}

In this section, it is clarified how PSS are described in the existing literature and which PSS understanding forms the basis of the examinations described in this paper. Subsequently, the state-ofthe-art of discrete-event modeling, which was used to simulate the system, is described.

\subsection{Product Service Systems}

PSS are systems consisting of products and services as well as supporting networks and infrastructures. They result in a lower environmental impact than traditional business models, for example by extending the product life cycle and optimizing consumption (as this results in savings for suppliers). They are competitive and meet individual customer needs. An added value for the customer results from the possibility of upgrading and modernizing the system or adapting it to changing requirements (Mont, 2002). They can be, therefore, described as a solution-oriented partnership with tangible and intangible components that does satisfy all stakeholders. Some authors see the use of PSS primarily in business-to-business relationships, but not in business to consumer relationships (Morelli, 2006). PSS can be described, for example, as a business-to-business application in the industrial sector. They are knowledge-intensive socio-technical systems that are characterized by the combined development, supply and use of product, and service parts. The solutions can adapt to changing customer requirements during the product life cycle (Meier et al., 2010).

A widespread and accepted classification of PSS was established by Tukker in 2004. New definitions are still being established, but they do not differ significantly from the existing ones (Tukker, 2015). In its classification, Tukker categorizes eight different types of PSS into three main categories (productoriented, use-oriented and result-oriented) to which different business models can be assigned (Tukker, 2004). The success of the development and implementation of PSS depends, on the one hand, on the ability to adapt quickly to changing customer requirements and, on the other hand, on the anticipation of these changes in the early phase of PSS development (Müller, 2014).

The value offered by the PSS to the user can be represented by properties that are linked to characteristics by relations. The characteristics describe product and service parts of the PSS and can be directly influenced by the developer. In addition, product and service parts of the system influence each other and can be represented as internal dependencies (Steinbach, 2005). Influences and framework conditions for a separately considered product part of the PSS are thus determined by internal dependencies to other product and service parts, the relationship to the properties, and external conditions. All these identify and define the requirements and inputs for the respective product parts. In many documented approaches of PSS development, the planning and design of the configurability and reconfigurability of PSS over the product life cycle are neglected, although the literature agrees that reconfiguring PSS during the life cycle reflects a significant advantage of it. This requires a 
combined development and thus a combined modeling of product and service parts by a common parametric data model (Schreiber et al., 2018).

As mentioned, for a coequal design of product and service parts, a model must be created in the early stages of the development process. This model must take into account external constraints and internal dependencies of the PSS, as well as changes on parts and their impact on other parts, in order to fully exploit its potential (Kloock-Schreiber et al., 2019).

\subsection{Discrete-event simulation}

Discrete-event (DE) is a traditional event-based simulation method that can describe the behavior of processes and services (Kreutzer, 1979). It has the capacity of including the dynamic of discrete systems with low to middle abstraction level. The model consists basically of entities, attributes, queues and resources that are submitted to distinct activities. These activities can be, e.g., generation, deletion, delay and joining of entities, or also mathematical calculations, that happen in discrete points in time (Banks, 2000). Furthermore, such simulations allow the implementation of probability distributions to control the sampling or other parameters, which is an advantageous stochastic approach (Borshchev and Filippov, 2004). Figure 1 depicts a simplistic model of a DE simulation using the open-source software JaamSim (Harrison et al., 2016). This model consists of the generation of entities with a normally distributed interval; queueing; seizing one resource to process the entity for an amount of time; release the resource; and, finally, deletion of the entity.

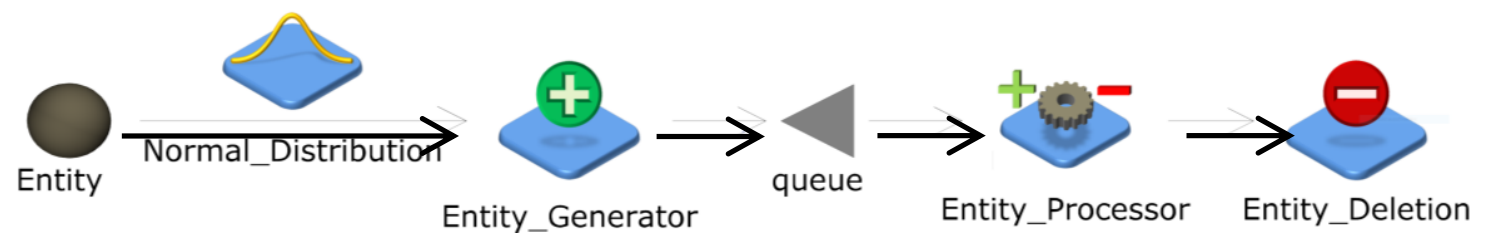

Figure 1. Basic DS model created in JaamSim

Despite very intuitive, these simulations allow a detailed analysis of costs, capacity, quality and time management. Therefore, DE models can be constructed to cover a large range of applications, such as queueing, computer, communication, manufacturing or traffic systems (Cassandras and Lafortune, 2009). One recent example that proves this flexibility was the application of DE for the simulation and optimization of a hospital service (Dosi et al., 2019). Moreover, an increasing interest is observed in the last years for simulation of PSS, as seen in the analysis performed in (Weidemann et al., 2015). As pointed out in their work, the use of DE for PSS has a high application potential, making possible three types of analysis:

- Result-oriented - used to model the entire process, including customer's and provider's side.

- Use-oriented - used to simulate the use of the product by the customer, in order to find the right amount of resources to deliver a quality service given certain uncertainties.

- Product-oriented - used to predict the behavior of the product in use and, thereby, adjust its specifications.

Besides the possibilities commented above, the simulation may also contain decision-making algorithms, which is a crucial part of holistic PSS modeling. This can be executed through the connection of data provided by the product use with the management of the service that these products deliver (Pidd, 2012).

As a drawback, the DE models have a dependency with human behavior, which must be approximated through distribution models and may cause a level of uncertainty. The modeling of such parameters requires a detailed field research that in many cases may be impractical, but can deliver good approximations if cyclic or seasonal behavior is present in the data.

\section{Modeling approach}

In order to design the specifications for products in PSS, in this work, four main areas are modelled from which the DE simulation is built. First, the scenario is modeled, which defines the restrictions and constraints of the model. The parameters here are defined by the scenario under consideration. 
The PSS is modeled from the parts product, service and decision making. These have different input parameters that are changed for parameter studies and the resulting effects are examined in the DES model. By comparing the input parameter sets, an optimum is derived for the respective scenario and the product specifications are defined. The underlying modeling approach is shown schematically in Figure 2.

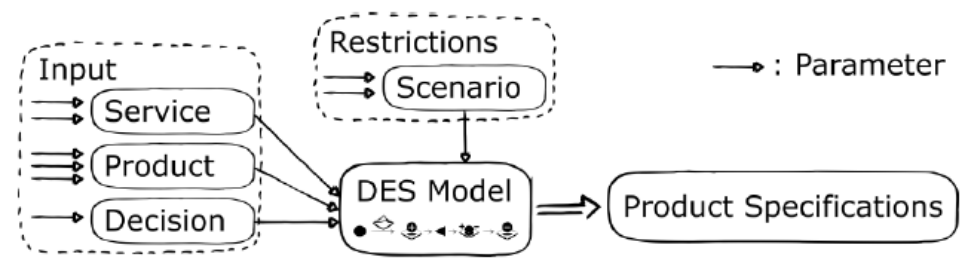

Figure 2. Structure of the modeling approach

In this paper, the simulations are executed with different products (coffee machines) to achieve minimal customer requirements. Finally, service and product costs for the different PSS setups are summed up in order to find the best specifications of product parameters.

\section{Case study modeling}

The PSS considered in the context of this paper is simplified and defined by a limited number of parameters and parts. It shows a business-to-business relationship in the gastronomy/hotel sector. The structure of this PSS example is shown in Figure 3. It can be classified as a result-oriented PSS which offers the customer a result regardless of how it is achieved. The supplier provides coffee cups for the hotel guests, delivering the necessary machines and exchanging them according to an increase or decrease in demand. In addition to the machines, the supplier also delivers the coffee beans (supplies the consumables) and maintains the machines. In this case, the customer is the hotel that pays the supplier to provide its guests with coffee cups.

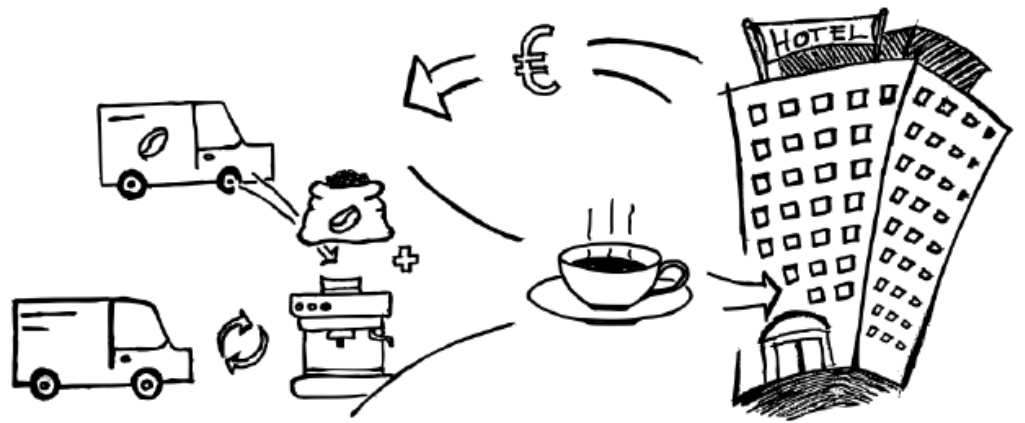

Figure 3. Result-oriented PSS for coffee supply to a hotel

Therefore, the PSS consists of two service parts and one product part. It should be noted here that if a PSS is to be developed holistically and coequal, this determination should only be made as late as possible in the development process and, in some cases, later modification is still possible. An example of this would be the cleaning of the machine, which could be carried out both by a service or by a machine equipped accordingly.

The modeling of this case study is divided into four sub-systems. The first one is the hotel scenario, where the size of the hotel, the seasonal occupancy, and the daily distribution of coffee cups consumption are considered. Next, the coffee machines are modelled as the product part of the system. The service parts are the supply of coffee beans and the necessary delivery or return of the coffee machines. Finally, the decision-making process for the management of the machines is also modeled and integrated into the system.

\subsection{Scenario modeling}

The application scenario is a hypothetical hotel, derived from an existing reference. In this case study, a hotel with a capacity of 300 beds and an average occupancy rate of approx. $70 \%$ was used. The 
consumption of coffee is 190,000 cups per year, which corresponds to an average consumption of 2.5 cups per person per day. In order to achieve a realistic simulation, the coffee cups consumption is distributed over the day, depending on the breakfast time, the coffee break and the intermediate times (shown in the diagram in Figure 4).

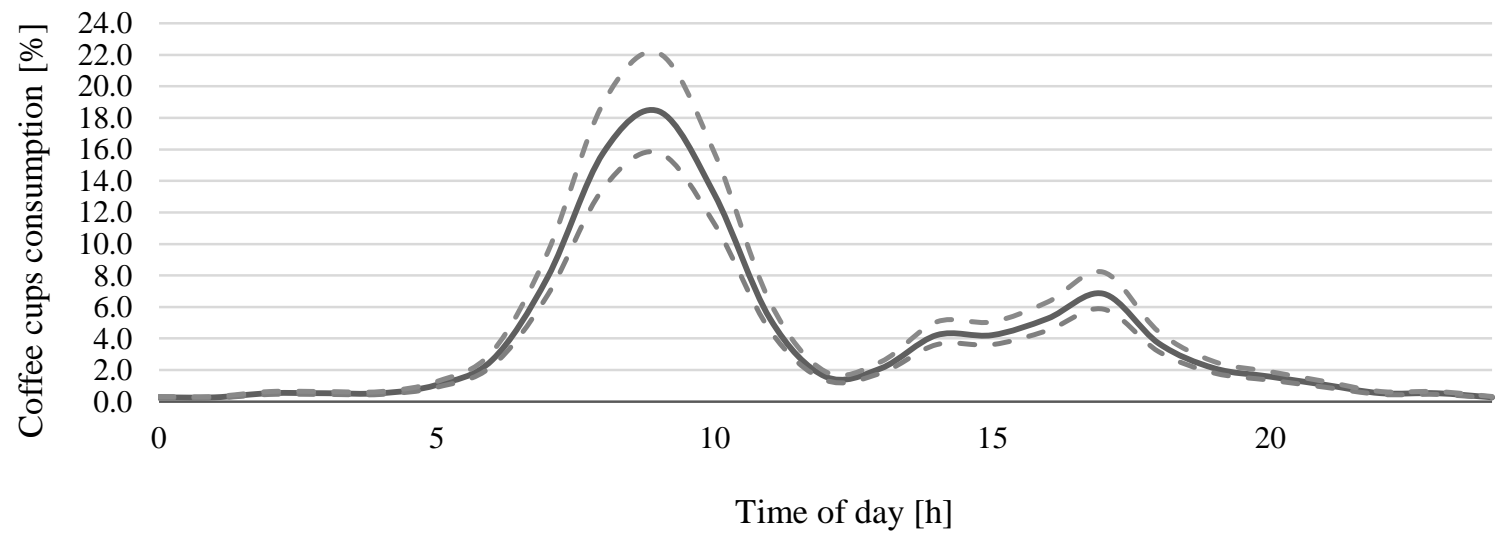

Figure 4. Distribution of coffee cups consumption in 24 hours

From this distribution, a related mean interval between coffee cups servings is derived for each daily hour. However, this serving mean interval is not constant and contains naturally deviations that will influence the creation of queues. To achieve a more realistic behaviour, a normal distribution was additionally used for this mean interval with a standard deviation of one-sixth of the mean value, represented as the dotted lines in Figure 4 (68.2\% interval).

In addition to the fluctuations spread over the day, the occupancy rate of the hotel is also taken into account. The hotel was simulated with a minimum basic occupancy rate of $40 \%$ and a distribution of occupancy rates based on holiday periods, which can be seen in Figure 5.

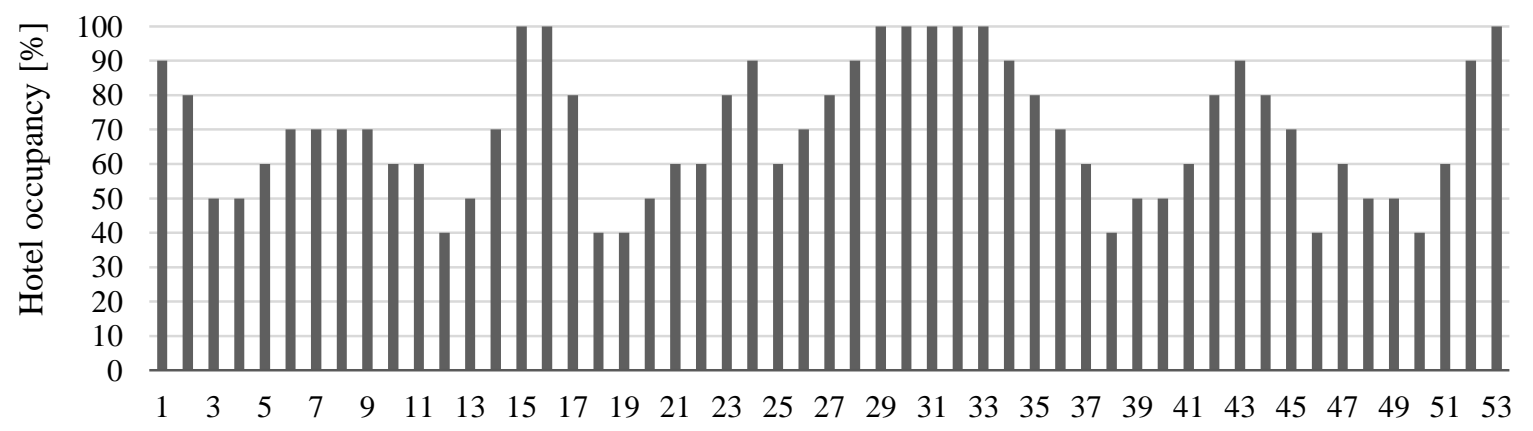

Calendar week

Figure 5. Distribution of hotel occupancy over one year

\subsection{Product modeling}

For the modeling of the machine, nine different variants were considered. The relevant parameters are the storage capacity, the output time and the cost of the machine. Naturally, the first two parameters, which are technical specifications, influence the third one, the machine cost. The storage capacity is here measured as how many coffee cups the machine can deliver with one single refill. An increase in storage capacity means that coffee beans have to be refilled less frequently. At the same time, the development effort and also the costs for a machine increase as less installation space is available for the other parts of the machine. The output time is related to how fast the machine can deliver one coffee cup. If the output time is increased, a higher number of coffee cups can be served in a certain amount of time. Equally, the costs increase with faster machines, since it has to be developed and equipped with more powerful mechanical components. 
Therefore, for the simulation, three storage capacity variants (200, 100 and 50 coffee cups) and three output times (90, 60 and $30 \mathrm{~s}$ ) were considered, resulting in the nine models listed in Table 1. The costs were estimated according to the technical specifications of the model.

Table 1. Machine model parameters

\begin{tabular}{|l|c|c|c|c|c|c|c|c|c|}
\hline Machine model & $\begin{array}{c}\text { Model } \\
1\end{array}$ & $\begin{array}{c}\text { Model } \\
2\end{array}$ & $\begin{array}{c}\text { Model } \\
3\end{array}$ & $\begin{array}{c}\text { Model } \\
4\end{array}$ & $\begin{array}{c}\text { Model } \\
5\end{array}$ & $\begin{array}{c}\text { Model } \\
6\end{array}$ & $\begin{array}{c}\text { Model } \\
7\end{array}$ & $\begin{array}{c}\text { Model } \\
8\end{array}$ & $\begin{array}{c}\text { Model } \\
9\end{array}$ \\
\hline $\begin{array}{l}\text { Storage Capacity [coffee } \\
\text { cups] }\end{array}$ & 200 & 100 & 50 & 200 & 100 & 50 & 200 & 100 & 50 \\
\hline Output time [s] & $90 \mathrm{~s}$ & $90 \mathrm{~s}$ & $90 \mathrm{~s}$ & $60 \mathrm{~s}$ & $60 \mathrm{~s}$ & $60 \mathrm{~s}$ & $30 \mathrm{~s}$ & $30 \mathrm{~s}$ & $30 \mathrm{~s}$ \\
\hline Machine cost per unit [u.] & 800 & 600 & 400 & 1,000 & 800 & 600 & 1,200 & 1,000 & 800 \\
\hline
\end{tabular}

Each parameter combination results in different requirements for the development of the machine. In addition to these parameters, it should be also mentioned that the simulated coffee machines are designed as smart products, since they independently check their utilization rate and the current storage.

\subsection{Service modeling}

For the service modeling the two service parts and the simulation relevant parameters, as well as necessary boundary conditions, are defined as follows.

Delivery and return of the machines: This service part of the PSS represents the exchange of machines at the customer's site. The necessary number of machines is adjusted by making further machines available with 20 minutes of delivery/installation time. The decision of when to deliver or return a machine is made by the supplier through a management system to be seen in the next section. The main expenses and costs that arise here are the costs for the transport (driver and vehicle) and the preparation of the machine. The reprocessing means the cleaning, but also the maintenance and servicing of the machines (which requires employees with an appropriate qualification). In the simulation, the exchange costs are defined with the value of $50 \mathrm{u}$. per delivery/return.

Supply of consumables: The second service part of this PSS includes the supply of coffee beans. This involves costs for transport (driver and vehicle), which is included in the simulation with a value of 5 u. per each executed refills.

In Table 2 the parameters for the simulation of the service modeling are summarized. The decisionmaking process can be seen as a part of the service modeling, but it was here separated due to its particularities, as will be seen in the next section.

Table 2. Service parameters

\begin{tabular}{|l|c|r|}
\hline Boundary condition & Value & Unit \\
\hline Delivery time & 20 & $\mathrm{~min}$ \\
\hline Machine exchange costs & 50 & $\mathrm{u}$ \\
\hline Coffee loading costs & 5 & $\mathrm{u}$ \\
\hline
\end{tabular}

\subsection{Decision-making modeling}

When simulating a holistic model of a PSS, an important point is decision-making modeling. In the present application example, they are related to how the machines will be managed in the system, regarding the delivery to the hotel and the return to the supplier's site. For that, control parameters must be defined to command when these two events take place. In this work, they are defined through thresholds.

By using the usage statistics of the machines that are already in place for a given period, one may define the thresholds through a limit where a machine is needed or unnecessary. For example, if the machines are active for the last 15 min more than $90 \%$ of the time, the supplier can interpret this data as an imminent need for a new machine. Therefore, the concept of mean active time per machine $(\bar{u})$ is used as parameter for this threshold. This is data that can be assessed by the supplier through a network connection with the machine and is defined in Equation (1).

$$
\bar{u}=\frac{\sum_{i}^{n} u_{i}(p)}{n}
$$


where $n$ is the number of machines at the customer's site; $u_{i}$ is the moving average of the percentage of time in which the machine was active serving coffee (function of $p$ ); and $p$ is the sampling period used to calculate the moving average. The delivery or return of machines happens, respectively, when the conditions seen in Equation (2) are met.

$$
D_{t h}<\bar{u}<R_{t h}
$$

where $D_{t h}$ is the delivery threshold; and $R_{t h}$ is the return threshold. In this work, however, the value of $\bar{u}$ was calculated with different sampling periods $(p)$ for each of the thresholds. The idea behind this is that the delivery must be fast enough to perceive a short-term increase in the mean active time and avoid the creation of queues and longer waiting times. Therefore, a delivery sampling period $p_{D}$ with shorter value must be defined. The return, however, must not be so sensible and can account for information from a longer period of time, so that unnecessary return is not executed. Therefore, the return sampling period $p_{R}$ is defined with a higher value. Within these concepts, the control parameters from Table 3 were applied.

Table 3. Control parameters

\begin{tabular}{|c|c|}
\hline$D_{t h}$ & $65 \%$ \\
\hline$p_{D}$ & $5 \mathrm{~min}$ \\
\hline$R_{t h}$ & $13 \%$ \\
\hline$p_{R}$ & $24 \mathrm{~h}$ \\
\hline
\end{tabular}

That means that if the machines are working more than $65 \%$ of the time for the last $5 \mathrm{~min}$, a new machine will be delivered, and vice-versa. These values were calibrated to achieve the necessary customer requirements for every machine model, as will be seen in the next section.

The supply of coffee beans refills was simulated with the assumption that the delivery is fast enough to avoid a lack of coffee beans in any of the machines in place. Thereby, a minimum of 10 coffee cups storage was set as the threshold when a new refill is needed. On every refill, all the machines are filled up to the maximum.

\section{Simulation and results}

Based on the classification provided in section 2.2, the model to be constructed is originally a resultoriented model. Therefore, the whole system was included in the model, from customer's and supplier's side, which involves the items shown in Table 4.

Table 4. Items present in the result-oriented model

\begin{tabular}{|l|l|}
\hline Entity / Resource & Related activities \\
\hline Coffee machine & Generation, delivery, use, return, deletion \\
\hline Coffee beans refill & Generation, delivery, use, deletion \\
\hline Coffee cup & $\begin{array}{l}\text { Generation, queuing, seize of coffee machine and coffee powder unit, } \\
\text { release of coffee machine, deletion }\end{array}$ \\
\hline
\end{tabular}

The coffee machine and coffee beans units are modeled both as entity and resource, since they must be generated and consumed by every order. As mentioned earlier, in this work, however, a holistic approach is constructed, where the aspects of service and product are modeled. Therefore, three main points must be essentially observed:

- The service must be efficient enough to achieve the desired quality, which is here the maximum waiting time of 2 min for a hotel guest to get a coffee cup.

- The product must be designed to offer the desired service and to minimize the costs related to the whole process.

- The scenario is kept constant for all simulations and, therefore, the revenue generated is equally kept constant. 
With th3 given machine parameters, control parameters and boundary conditions, the model was submitted for the simulation of a whole year. The following results shown in Table 5 were achieved regarding the models with different output times.

Table 5. Simulation results, part 1

\begin{tabular}{|l|l|l|l|}
\hline & Model 1-3 & Model 4-6 & Model 7-9 \\
\hline Max queueing time & $1,1 \mathrm{~min}$ & $1,8 \mathrm{~min}$ & $0,1 \mathrm{~min}$ \\
\hline Average machine time in use & $11,9 \%$ & $11,5 \%$ & $9,4 \%$ \\
\hline Average number of machines & 4,52 & 3,13 & 1,92 \\
\hline Maximum number of machines & 6 & 4 & 3 \\
\hline Number of machine delivered/returned & 34 & 22 & 36 \\
\hline
\end{tabular}

As seen, all the simulations provided the necessary service quality parameter of a maximum queueing time of less than $2 \mathrm{~min}$. Despite model 7-9 have presented a superior service performance, this result is here not further analyzed, since this is not a service-oriented simulation. Furthermore, it can be seen that the number of machines required to decrease with the models that have a shorter output time. In regard to the different storage capacities of each machine, different results were achieved for the number of executed refills, as seen in Table 6.

Table 6. Simulation results, part 2

\begin{tabular}{|l|c|c|c|c|c|c|c|c|c|}
\hline Machine model & Model & Model & Model & Model & Model & Model & Model & Model & Model \\
& 1 & 2 & 3 & 4 & 5 & 6 & 7 & 8 & 9 \\
\hline Number of refills & 210 & 425 & 870 & 306 & 624 & 1285 & 501 & 1027 & 2178 \\
\hline
\end{tabular}

The different results achieved are caused not only by the different machine storage capacities but also by the number of machines present in place. As seen in Table 5, the models that have shorter output time require fewer machines in place and, because of that, a higher number of coffee beans refills is necessary. When taking the total costs into consideration (machine, delivery/return, and refill costs), an overview of the final results can be presented, as depicted in Figure 6.

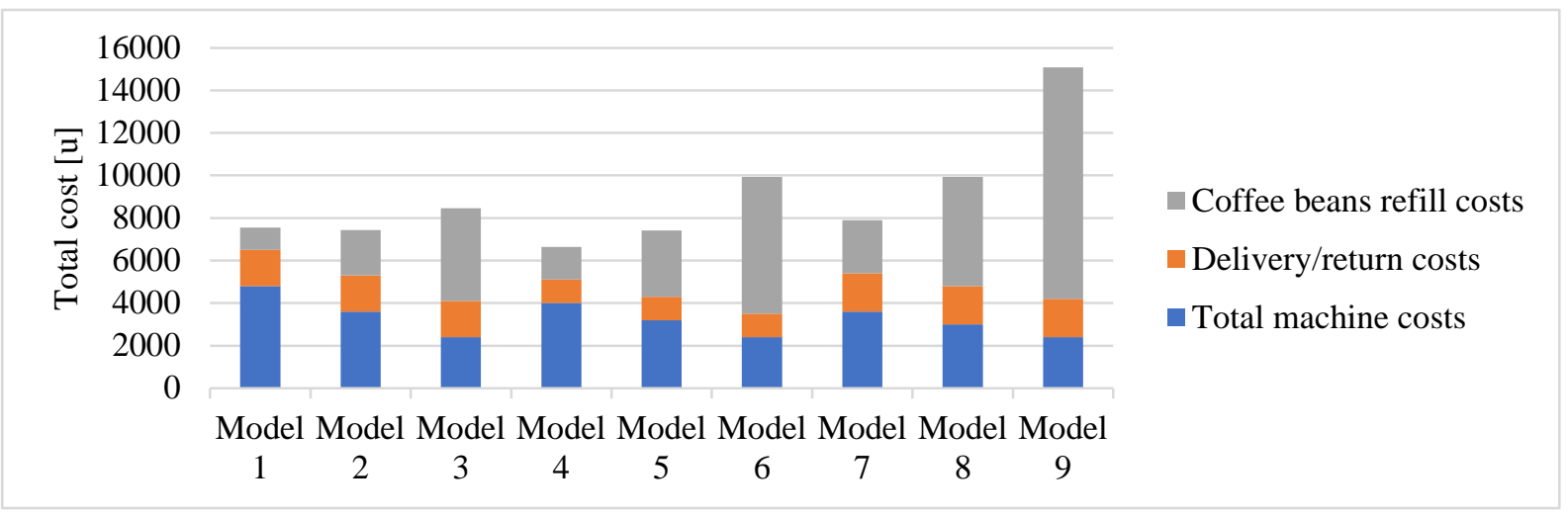

Figure 6. Costs results overview

\section{Discussion and conclusion}

Differently from conventional PSS models, where the customer would pay for a machine rental or supply separately, the proposed model in this work is the sale of a pure service with the management of the product by the supplier only. The objective was, therefore, to optimally use the products and to decrease total costs. Despite the hypothetical scenario, the results were able to show that not always the best product is the most suitable for a PSS. In the example presented, the fastest machines (model 7-9) required a less number of machines in place, but even the one with the highest storage capacity (model 7) was not able to reduce the total cost at a minimum level. The most suitable machine model for this PSS 
was model 4, which could diminish the number of refills and the total costs, despite the higher machine costs. This is an innovative use of a result-oriented simulation, where the use requirements were constantly observed and the product specifications were optimized. Therefore, the given holistic approach proves to be advantageous for the design of products for PSS and answers the research question.

The customer's environment modeling can be challenging in new system development. In the example, the coffee consumption in the hotel presents essential uncertainties that are difficult to quantify without previous examination. However, the seasonal effect, in this case, can be simulated with a satisfactory confidence level. Furthermore, with the smart products already in place, the consumption data can be continuously saved, increasing the quality of the predictions as the product is used. Therefore, the use of smart products in PSS stands out as an essential advantage. The information about the product's use is not only important to deliver a quality service but also for better management of the products. Thereby, the right machine will be sent to the place where it is most needed, increasing the efficiency of the PSS.

For the service side, the events can be very precisely simulated. In the presented model, this was implemented through a few parameters, but a greater number of components can be equally inserted for real cases. Thereby, a fully extended environment can be modeled, where many customers from different types, different machines, and more uncertainty are present. For this end, an automatic variation of the simulation parameters and following submission would be essential. The use of opensource software makes such an approach possible in future works.

The automation of the simulations is especially important when dealing with the decision-making parameters. Decision-making is an essential part of PSS and, as seen, it can have a strong influence on the final result. Many different mathematical models or artificial intelligence systems can be used to deal with this problem and, for each of them, an optimal use of control parameters can be found to optimize the costs. Each machine model might need its own decision-making parameters to increase the PSS efficiency.

In addition, the DES is dependent on the concrete definition of parameters and rules. This can be particularly problematic in the course of a development if not all areas of the system have been designed and defined. Further research will therefore also investigate whether other simulation methods, such as System Dynamics, can be integrated into the development process to replace or supplement the DES.

\section{Acknowledgement}

This research was conducted in the scope of the research project SmartHybrid - Product Engineering (ID: 85003608) which is partly funded by the European Regional Development Fund (ERDF) and the State of Lower Saxony (Investitions- und Förderbank Niedersachsen NBank). We like to thank them for their support.

\section{References}

Aurich, J.C., Fuchs, C. and Wagenknecht, C. (2006), "Life cycle oriented design of technical Product-Service Systems", Journal of cleaner production, Vol. 14 No. 17, pp. 1480-1494. https://doi.org/10.1016/j.jclepro. 2006.01.019

Banks, J. (2000), "Introduction to simulation", Proceedings of the 1994 Winter Simulation Conference. https://doi.org/10.1109/WSC.1999.823046

Borshchev, J. and Filippov, A. (2004), "From system dynamics and discrete event to practical agent based modeling: reasons, techniques, tools”, 22nd International Conference of the System Dynamics Society.

Cassandras, C.G. and Lafortune, S. (2009), Introduction to discrete event systems, Springer Science \& Business Media. https://doi.org/10.1007/978-0-387-68612-7

Dosi, C. et al. (2019), “Computational Simulation as an organizational prototyping tool", Proceedings of the Design Society: International Conference on Engineering Design. https://doi.org/10.1017/dsi.2019.116

Gembarski, P.C. and Lachmayer, R. (2016), "Mass Customization und Product-Service-Systems: Vergleich der Unternehmenstypen und der Entwicklungsumgebungen [Mass customization and product service systems: comparison of company types and development environments]", In: Tagungsband der Dienstleistungsmodellierung 2016 (DLM 2016), Karlsruhe.

Gembarski, P.C. (2020), "The Meaning of Solution Space Modelling and Knowledge-Based Product Configurators for Smart Service Systems", In: Borzemski, L., Świątek, J. and Wilimowska, Z. (Eds.), Information Systems Architecture and Technology: Proceedings of 40th Anniversary International Conference on Information 
Systems Architecture and Technology - ISAT 2019, Advances in Intelligent Systems and Computing, Vol. 1050, Springer International Publishing, Cham, pp. 28-37. https://doi.org/10.1007/978-3-030-30440-9_4

Harrison, H., King, H. and Paour, P.-L. (2016), "Jaamsim: Release 2016-14”, Zenodo. https://doi.org/10.5281/ zenodo. 57118

Kloock-Schreiber, D. et al. (2019), "Enrichment of Geometric CAD Models for Service Configuration", in 21th International Configuration Workshop Proceedings of the 21th International Configuration Workshop, pp. 22-29.

Kreutzer, W. (1979), "Computer system modelling and simulation", ACM SIGMETRICS Performance Evaluation Review, Vol. 8 No. 1-2, pp. 9-35.

Meier, H., Roy, R. and Seliger, G. (2010), "Industrial product-service systems-IPS2", CIRP annals, Vol. 59 No. 2, pp. 607-627. https://doi.org/10.1016/j.cirp.2010.05.004

Mont, O.K. (2002), "Clarifying the concept of product-service system", Journal of cleaner production, Vol. 10 No. 3, pp. 237-245. https://doi.org/10.1016/S0959-6526(01)00039-7

Morelli, N. (2006), "Developing new product service systems (PSS): methodologies and operational tools", Journal of cleaner production, Vol. 14 No. 17, pp. 1495-1501. https://doi.org/10.1016/j.jclepro.2006.01.023

Müller, P. (2014), "Integrated engineering of products and services: Layer-based development methodology for product-service systems", Fraunhofer Verlag. ISBN 978-3-8396-0549-3

Pidd, M. (2012), "Mixing other methods with simulation is no big deal", Proceedings of the 2012 Winter Simulation Conference. https://doi.org/10.1109/WSC.2012.6465280

Schreiber, D., Gembarski, P.C. and Lachmayer, R. (n.d.), "Developing a constraint-based solution space fpr product-service systems", Proceedings of the 8th International Conference on Mass Customization and Personalization - Community of Europe, MCP-CE, pp. 240-249.

Schreiber, D., Gembarski, P.C. and Lachmayer, R. (2018), "Datamodels for PSS Development and Configuration: Existing Approaches and Future Research", in Customization 4.0, Springer, pp. 55-74. https://doi.org/10.1007/978-3-319-77556-2_4

Steinbach, M. (2005), Systematische Gestaltung von product-service-systems: integrierte Entwicklung von product-service-systems auf Basis der Lehre von Merkmalen und Eigenschaften [Systematic design of product service systems], LKT. ISBN: 3-930429-64-0

Sturm, F., Bading, A. and Schubert, M. (2007), Investitionsgüterhersteller auf dem Weg zum Lösungsanbieter: eine empirische Studie [Capital goods manufacturers on the way to becoming solution providers: an empirical study];[fit2solve], Fraunhofer-IRB-Verlag. ISBN: 9783816773962

Thomas, O., Walter, P. and Loos, P. (2010), "Konstruktion und anwendung einer entwicklungsmethodik für product-service systems" [Design and application of a development methodology for product-service systems], in Hybride Wertschöpfung, Springer, pp. 61-81. https://doi.org/10.1007/978-3-642-11855-5_4

Tukker, A. (2004), "Eight types of product-service system: eight ways to sustainability? Experiences from SusProNet", Business strategy and the environment, Vol. 13 No. 4, pp. 246-260. https://doi.org/ $10.1002 /$ bse.414

Tukker, A. (2015), "Product services for a resource-efficient and circular economy-a review", Journal of cleaner production, Vol. 97, pp. 76-91. https://doi.org/10.1016/j.jclepro.2013.11.049

Weidemann, D. et al. (2015), "Product-service system development with discrete event simulation", in IEEE systems conference (SysCon). https://doi.org/10.1109/SYSCON.2015.7116741 